\title{
DPOAJ
}

Dohara Publisher Open Access Journal

Volume 01, No.02, Oktober.2021 e-ISSN 2807-7539, p-ISSN 2807-7547

\section{Original Artikel \\ Pengaruh Terapi Akupunktur dan Meditasi pada Wanita Kelebihan Berat Badan dan Obesitas: Studi Kasus}

(The Effects of Acupuncture and Meditation on Slimming Indices in Overweight and Obese Women: Case Series Study)

\author{
Lenny Dwinijanti ${ }^{1,3}$, Willie Japaries ${ }^{3}$, Harliansyah ${ }^{2,3}$ \\ ${ }^{1}$ Institute of L-Health and Beauty Clinic, Jakarta, Indonesia \\ ${ }^{2}$ Department of Biochemistry Faculty of Medicine University of YARSI, Jakarta, Indonesia \\ ${ }^{3}$ Indonesia's Nalanda Buddhist Traditional Chinese Medicine College \\ japariesw@yahoo.com
}

\begin{abstract}
Introduction: Overweight and obesity not only affect an individual's health physically but also psychologically. So, it is imperative for a clinician to take care both aspects of the individuals.

Methods: This study is to report the effects of acupuncture and meditation therapy on the slimming indices of the overweight and obese women visiting our aesthetic clinic. They were voluntarily segregated into two groups, ie. one group consisted of women who selected acupuncture therapy (AT) only, the other group consisted of women who selected acupuncture and meditation therapy (AMT). Both groups' body mass index (BMI) and waist circumference (WC) were measured at the first visit and after eight and sixteen sessions of therapy, respectively. The differences between pre-therapy and post-therapy indices and between AT and AMT groups were analysed using two tailed t-test at 95\% confidence interval (alpha at 0.05).
\end{abstract}

Results: Subjects were seventeen women with overweight and obesity visiting aesthetic clinic for slimming treatment. Ten women chose AT and seven women chose AMT. After eight and sixteenth sessions of therapy, both AT and AMT groups show very significant reduction in the BMI and WC $(\mathrm{P}<0.01)$. The AMT subjects reported that they felt more relaxed and refreshed, and continued meditation practice at home.

Discussion: The subjects that chose AMT have significantly lower BMI at the first visit compared to the subjects that chose AT, ie. BMI at $24,33 \pm 0,97 \mathrm{~kg} / \mathrm{m}^{2}$ and $28,00 \pm 2,08 \mathrm{~kg} / \mathrm{m}^{2}(\mathrm{P}<0.01)$, respectively. The age of AMT subjects is in average significantly older than AT subjects, ie. 34,42 $\pm 5,99$ years and $29,2 \pm 4,9$ years respectively $(\mathrm{P}<0.01)$. This may indicate that at the initial or milder state of gaining overweight or obesity, as well as the older women were more aware of the need to seek tranquillity or to overcome the stressful mind through meditation practice.

Keywords: Traditional Chinese Medicine, Overweight, Obesity, Acupuncture, Meditation

\author{
Artikel \\ Disubmit (Received) : 12 September 2021 \\ Diterima (Accepted) : 24 September 2021 \\ Diterbitkan (Published) : 19 Oktober 2021
}

Copyright: (C) 2021 by the authors. License DPOAJ, Jakarta, Indonesia. This article is an open access article distributed under the terms and conditions of the Creative Commons Attribution (CC BY SA) license (https:// creativecommons.org/licenses/by/ 4.0/) 


\section{Pendahuluan}

Kelebihan berat badan dan obesitas merupakan masalah kesehatan di seluruh dunia. Menurut estimasi para ahli, sekitar 7\% dari populasi orang dewasa di dunia termasuk obesitas, dan dua hingga tiga kali lipat dari itu tergolong kelebihan berat badan. ${ }^{1,2}$ Berdasarkan klasifikasi WHO, untuk masyarakat di kawasan Asia Pasifik, individu dengan IMT (indeks masa tubuh) $23 \mathrm{~kg} / \mathrm{m}^{2}$ atau lebih adalah kelebihan berat badan, sedangkan individu dengan IMT $25 \mathrm{~kg} / \mathrm{m}^{2}$ atau lebih adalah obesitas. ${ }^{2}$ Individu dengan kelebihan berat badan dan obesitas memiliki risiko lebih tinggi untuk terkena berbagai penyakit metabolik, termasuk diabetes mellitus, hipertensi, dislipidemia, penyakit kardiovaskular, dan apnea tidur. ${ }^{1,2}$ Selain gangguan fisik metabolik, mereka juga terpajan masalah psikologis yaitu citra diri yang buruk, terganggunya kualitas hidup, dan bahkan depresi pada individu obesitas berat. ${ }^{1,2}$ Khususnya kaum wanita lebih rentan merasa tertekan untuk dapat memiliki bentuk tubuh yang ideal, dibandingkan dengan kaum pria., ${ }^{2,3}$

Oleh karena itu, penatalaksanaan terhadap kelebihan berat badan dan obesitas perlu bersifat komprehensif, bukan hanya tertuju kepada aspek fisik, tapi juga aspek psikologisnya. Salah satu metode non-farmakologis efektif untuk mengatasi obesitas adalah akupunktur. ${ }^{1}$ Sedangkan metode praktis untuk mengatasi masalah psikologis ansietas yang dapat dilakukan bersamaan dengan akupunktur adalah meditasi. ${ }^{4}$ Dalam praktik, kedua metode tersebut telah dipadukan dalam menangani para pasien kelebihan berat badan, dan obesitas. Berikut ini hasil analisis awal terhadap kasus-kasus yang ditangani dengan kedua metode tersebut.

\section{Metode}

Para subjek adalah wanita dengan kelebihan berat badan, dan obesitas yang diterapi antara bulan April hingga Oktober tahun 2020. Semua subjek diperiksa secara klinis, khususnya data tekanan darah, berat badan, tinggi badan, lingkar pinggang, dan anamnesis untuk menyingkirkan penyakit serius seperti keganasan, penyakit kardio-serebrovaskular berat, gagal ginjal, kehamilan, dan lainnya. Setiap selesai terapi subjek juga ditanya perasaannya apakah merasa lebih rileks dan apakah terdapat keluhan. Para subjek diberikan kebebasan untuk memilih antara diterapi dengan akupunktur saja (TA) atau dengan akupunktur disertai meditasi (TAM).

Terapi akupunktur yang dilakukan adalah metode Jin Three Needles, ${ }^{5,6}$ dengan jarum akupunktur nontraumatik steril berukuran satu, dan satu setengah inci. Setiap kali terapi berlangsung 20 menit, dengan interval tiga hari atau dua kali dalam seminggu. Titik penjaruman yang dipilih adalah mencakup CV10 (Xiawan), CV13 (Shangwan), CV6 (Qihai), CV12 (Zhongwan), GB26 (Daimai), ST36 (Zusanli), ST25 (Tianshu), dan PC6 (Neiguan). Sedangkan, terapi meditasi yang diberikan adalah dengan cara membimbing pasien untuk relaksasi, dan memusatkan seluruh perhatian pada keluar masuknya napas. ${ }^{4}$ Meditasi dilakukan selama 20 menit, dimulai sejak jarum ditusukkan ke titik-titik akupunktur, dan selesai ketika jarum-jarum dicabut. Seluruh pasien telah menandatangani surat persetujuan diterapi dan mengizinkan datanya digunakan dalam penelitian dengan menjaga kerahasiaan pribadinya.

Parameter kelangsingan tubuh, yaitu IMT, dan lingkar pinggang (LP) diambil dari rekam medik pasien pada kunjungan pertama, kunjungan ke delapan, dan ke enam belas untuk menilai efektivitas terapi. Uji statistik yang digunakan untuk menilai perbedaan parameter kelangsingan tubuh sebelum dan sesudah terapi adalah dengan tes berpasangan, dua ekor. Kalkulasi memakai program statistic pada Microsoft Excel. Batas kemaknaan pada tingkat keyakinan 95\% atau alfa 0.05.

\section{Hasil}

Seluruh subjek yang terdata selama periode penelitian berjumlah 17 orang, 10 orang memilih terapi dengan akupunktur saja (TA), dan 7 orang memilih akupunktur dengan meditasi (TAM). Semua subjek adalah wanita dengan IMT kelebihan berat badan berdasarkan batasan WHO untuk kawasan Asia Pasifik, yaitu IMT $\geq 23 \mathrm{~kg} / \mathrm{m} 2$. Usia subjek berkisar antara 25 hingga 40 tahun. Usia subjek yang memilih TAM $(\mathrm{n}=7)$ secara signifikan lebih tua dibandingkan subjek yang memilih TA $(\mathrm{n}=10)$, yakni masing-masing $34,42 \pm 5,99$ tahun dan $29,2 \pm 4,9$ tahun $(\mathrm{P}<0.05)$. Pada awal terapi, IMT 
subjek yang memilih TAM $(\mathrm{n}=7)$ secara signifikan lebih rendah dibandingkan subjek yang memilih TA ( $\mathrm{n}=10)$, yakni masing-masing $24,33 \pm 0,97 \mathrm{~kg} / \mathrm{m} 2$ dan $28,00 \pm 2,08 \mathrm{~kg} / \mathrm{m} 2(\mathrm{P}<0.01)$. Perbedaan IMT antara subjek AMT, dan AT terutama disebabkan perbedaan berat badan, sedangkan tinggi badan kedua kelompok tidak berbeda bermakna $(\mathrm{P}=0.601,>0.05)$.

Setelah menjalani terapi, baik kelompok TA maupun TAM menunjukkan penurunan semua parameter pelangsingan tubuh $(\mathrm{P}<0.01)$. Penurunan nilai IMT dan LP subjek sudah terukur signifikan pada terapi ke delapan, dan menurun lebih lanjut pada terapi ke enam belas.

IMT dari subjek TAM menunjukkan penurunan signifikan, yaitu dari $28,00 \pm 2,08 \mathrm{~kg} / \mathrm{m} 2$ menjadi $24,57 \pm 1,89 \mathrm{~kg} / \mathrm{m} 2(\mathrm{P}<0.01)$ pada terapi ke delapan, dan menjadi $22,20 \pm 1,91 \mathrm{~kg} / \mathrm{m} 2(\mathrm{P}<0.01)$ pada terapi ke enam belas. Sedangkan, IMT subjek TA menunjukkan penurunan signifikan pula, dari $24,33 \pm 0,97 \mathrm{~kg} / \mathrm{m} 2$ menjadi $22,08 \pm 0,89 \mathrm{~kg} / \mathrm{m} 2 \quad(\mathrm{P}<0.01)$ pada terapi ke delapan, dan menjadi $20,46 \pm 0,87 \mathrm{~kg} / \mathrm{m} 2(\mathrm{P}<0.01)$ pada terapi ke enam belas.

LP dari subjek TA menunjukkan penurunan signifikan pula, yaitu dari 87,50 $\pm 6,08 \mathrm{~cm}$ menjadi $81,40 \pm 7,73 \mathrm{~cm}$ pada terapi ke delapan, dan menjadi 76,90 $\pm 7,99 \mathrm{~cm}(\mathrm{P}<0.01)$ pada terapi ke enam belas. Sedangkan LP subjek TAM juga menunjukkan penurunan signifikan, yaitu dari $86,28 \pm 5,82 \mathrm{~cm}$ menjadi $81,85 \pm 5,92 \mathrm{~cm}$ pada terapi ke delapan, dan menjadi 78,28 $\pm 5,28 \mathrm{~cm}(\mathrm{P}<0.01)$ pada terapi ke enam belas. Lihat Tabel-1 untuk data terinci masing-masing subjek.

Pada subjek TAM yang mendapatkan arahan terapi meditasi sewaktu diterapi akupunktur, mereka melaporkan merasa ketenangan dan relaksasi. Mereka juga meneruskan praktik meditasi di rumah, karena merasa lebih tenang, segar, dan emosinya lebih terkendali. Seluruh subjek tidak menunjukkan adanya efek buruk selama periode diterapi.

Tabel 1. Data usia, berat badan, tinggi badan, IMT, LP, seluruh subjek pada kunjungan pertama, ke delapan, dan ke enam belas

\begin{tabular}{|c|c|c|c|c|c|c|c|c|c|}
\hline No. & $\begin{array}{l}\text { Usia } \\
\text { (tahun) }\end{array}$ & $\begin{array}{l}\mathrm{BB} \\
(\mathrm{kg})\end{array}$ & $\begin{array}{l}\mathrm{TB} \\
(\mathrm{cm})\end{array}$ & $\begin{array}{l}\text { IMT-t }_{0} \\
\left(\mathrm{~kg} / \mathrm{m}^{2}\right)\end{array}$ & $\begin{array}{l}\text { LP-t }{ }_{0} \\
(\mathrm{~cm})\end{array}$ & $\begin{array}{l}\text { IMT-t } 8 \\
\left(\mathrm{~kg} / \mathrm{m}^{2}\right)\end{array}$ & $\begin{array}{l}\text { LP-t }{ }_{8} \\
(\mathrm{~cm})\end{array}$ & $\begin{array}{c}\text { IMT-t }_{16} \\
\left(\mathrm{~kg} / \mathrm{m}^{2}\right)\end{array}$ & $\begin{array}{l}\text { LP-t }{ }_{16} \\
(\mathrm{~cm})\end{array}$ \\
\hline & \multicolumn{9}{|c|}{ Subjek yang diterapi dengan akupunktur saja (TA) } \\
\hline 1 & 35 & 73 & 164 & 27,14 & 88 & 23 & 74 & 20,07 & 68 \\
\hline 2 & 25 & 73 & 153 & 31,18 & 81 & 23 & 70 & 20,50 & 65 \\
\hline 3 & 25 & 76 & 168 & 26,92 & 85 & 25,1 & 80 & 23,03 & 75 \\
\hline 4 & 25 & 73 & 165 & 26,81 & 84 & 24,2 & 80 & 21,67 & 75 \\
\hline 5 & 30 & 65,9 & 161 & 25,42 & 86 & 21,6 & 80 & 19,28 & 75 \\
\hline 6 & 35 & 83 & 162 & 31,62 & 99 & 28,3 & 94 & 25,52 & 90 \\
\hline 7 & 25 & 64 & 150 & 28,44 & 86 & 25,5 & 81 & 23,55 & 77 \\
\hline 8 & 25 & 63 & 147 & 29,15 & 84 & 26,3 & 80 & 23,60 & 77 \\
\hline 9 & 30 & 74,3 & 165 & 27,29 & 84 & 24,7 & 80 & 23,14 & 77 \\
\hline 10 & 37 & 65 & 158 & 26,03 & 98 & 24 & 95 & 21,63 & 90 \\
\hline & \multicolumn{9}{|c|}{ Subjek yang diterapi dengan akupunktur dan meditasi (TAM) } \\
\hline 11 & 30 & 59,7 & 160 & 23,32 & 89 & 21,3 & 86 & 19,72 & 82 \\
\hline 12 & 25 & 66 & 162 & 25,14 & 80 & 23 & 77 & 21,33 & 74 \\
\hline 13 & 38 & 57 & 157 & 23,12 & 86 & 20,6 & 81 & 19,06 & 77 \\
\hline 14 & 38 & 67,3 & 168 & 23,84 & 83 & 22,3 & 80 & 21,08 & 77 \\
\hline 15 & 30 & 49,5 & 143 & 24,20 & 81 & 22 & 74 & 20,04 & 71 \\
\hline 16 & 40 & 65 & 159 & 25,71 & 97 & 23,1 & 92 & 21,35 & 87 \\
\hline
\end{tabular}




\section{DPOA}

Dohara Publisher Open Access Journal

Volume 01, No.02, Oktober.2021

e-ISSN 2807-7539, p-ISSN 2807-7547

17

\begin{tabular}{l|l|l}
40 & 60 & 155
\end{tabular}

24,97 $\quad 88$

22,3

83

20,60

80

Keterangan: BB: berat badan, TB: tinggi badan, IMT: indeks masa tubuh, LP: lingkar pinggang, $\mathrm{t}_{0}$ : kunjungan pertama, $\mathrm{t}_{8}$ : kunjungan ke delapan, $\mathrm{t}_{16}$ : kunjungan ke enam belas.

\section{Pembahasan}

Kelebihan berat badan dan obesitas merupakan masalah kesehatan masyarakat di dunia dewasa ini. ${ }^{1}$ Untuk mengatasi masalah tersebut, belakangan ini semakin banyak penderita yang memilih cara alami seperti TCM. Berdasarkan sebuah kajian sistematik baru-baru ini, metode terapi obesitas secara TCM yang mencakup terapi akupunktur, herbal, olah pikir, dan pengaturan makanan, terbukti lebih efektif dibandingkan plasebo dan intervensi pola hidup, bahkan efeknya sebanding dengan obatobatan anti-obesitas. ${ }^{7}$ Laporan kasus ini mendukung hasil kajian sistematis tersebut. Penurunan terhadap parameter kegemukan tubuh, khususnya IMT, dan LP sangat signifikan setelah delapan kali terapi akupunktur dengan atau tanpa meditasi. Penurunan parameter kegemukan pada subjek yang diteliti dalam studi ini jauh lebih mencolok dibandingkan yang dilaporkan oleh peneliti lain., ${ }^{7,9}$ Hal ini mungkin disebabkan oleh subjek dalam penelitian ini memiliki IMT yang lebih rendah dibandingkan subjek pada penelitian lainnya. Hal ini dapat menunjukkan, bahwa intervensi lebih awal sewaktu IMT belum meningkat lebih jauh membawa hasil yang lebih signifikan.

Dalam penelitian ini, subjek yang memilih diterapi dengan akupunktur dan meditasi (TAM) memiliki IMT yang lebih rendah $(\mathrm{P}<0.01)$ dibandingkan yang memilih diterapi akupunktur saja (TA). Hal ini dapat menunjukkan subjek dengan IMT lebih rendah atau pada fase awal peningkatan berat badan memiliki kesadaran lebih tinggi untuk mencari kondisi relaksasi dengan meditasi. Selain itu, tampak bahwa usia rata-rata subjek yang memilih TAM lebih tua secara signifikan dibandingkan subjek yang memilih TA, hal ini sesuai dengan laporan hasil meta-analisis, bahwa wanita obesitas dengan usia lebih senior lebih sering berkaitan dengan rasa cemas. ${ }^{10}$

Menurut teori TCM, penyebab dari kegemukan atau obesitas adalah karena organ limpalambung terlalu banyak mencerna makanan manis berminyak. ${ }^{5}$ Karena limpa-lambung bekerja terlalu berat, maka lama kelamaan fungsinya terganggu. Akibatnya, metabolisme sari pati makanan minuman menjadi tersendat, dan menghasilkan dahak keruh yang terakumulasi menyebabkan kegemukan dan obesitas. ${ }^{5}$ Maka dari itu, metode terapi terhadap kelebihan lemak tubuh atau kelebihan berat badan dan obesitas, seperti diuraikan dalam metode penelitian di atas adalah dengan melakukan stimulasi terhadap titik-titik akupunktur yang berefek menormalkan kembali fungsi organ limpa-lambung. . $^{511,12}$

Penelitian biomedis menunjukkan mekanisme kerja akupunktur dalam terapi obesitas adalah dengan mempengaruhi kadar hormon, antara lain insulin, leptin, ghrelin dan kolesistokinin pada subjek obesitas. ${ }^{13}$ Berbagai hormon tersebut mempengaruhi metabolisme dan fungsi organ digestif. Jadi, terdapat kesamaan antara TCM dan ilmu medis dalam penatalaksanaan kasus kelebihan berat badan, dan obesitas, yakni dengan menormalkan fungsi sistem digestif atau organ limpa-lambung dalam istilah TCM. Maka dari itu, tidak mengherankan bahwa banyak kajian sistematis dan metaanalisis menyimpulkan terapi akupunktur efektif dan rasional dalam penatalaksanaan kelebihan berat badan dan obesitas. ${ }^{7,9,14}$

Keterkaitan antara rasa cemas dengan kegemukan atau obesitas pun sudah banyak dilaporkan. ${ }^{15,16}$ Untuk itu, dalam tata laksana terhadap pasien kelebihan berat badan dan obesitas perlu diberikan pula terapi atau nasehat untuk meredakan kecemasan. Dalam penelitian ini digunakan terapi meditasi yang sudah terbukti efektif mengatasi rasa cemas. ${ }^{17}$

Ternyata pada subjek yang diberikan terapi meditasi selama diakupunktur merasakan manfaat signifikan meditasi dalam menenangkan perasaan, menimbulkan relaksasi, membuat emosi lebih terkendali, dan meredakan stres, sehingga mereka melanjutkan praktik meditasi di rumah.

Dapat disimpulkan studi kasus ini menunjukkan akupunktur efektif mengurangi parameter kegemukan fisik, khususnya IMT dan LP dalam waktu satu bulan. Akupunktur yang disertai meditasi membawa manfaat tambahan bagi pasien, khususnya dalam mengatasi rasa cemas, dan mengendalikan emosinya. Oleh sebab itu, kombinasi terapi akupunktur dan meditasi layak sebagai salah satu pilihan pertama dalam mengatasi kelebihan berat badan, dan obesitas. 


\section{DPOAJ}

\section{References}

1. Lacey JM, Thershakovec AM., Foster GD. Acupuncture for the treatment of obesity: a review of the evidence. International Journal of Obesity. 2003;27: 419-427. Available at: https://www.nature.com/articles/0802254/. Accessed 29 March 2021.

2. Lim JU, Lee JH, Kim JS, et al. Comparison of World Health Organization and Asia-Pacific body mass index classifications in COPD patients. Int J Chron Obstruct Pulmon Dis. 2017; 12:24652475. Available at: https://www.ncbi.nlm.nih.gov/pmc/articles/PMC5571887/. Accessed 28 August 2021.

3. Dixit SS, Luqman N. Body Image, Social Anxiety and Psychological Distress among Young Adults. J Psychol Clin Psychiatry2018; 9(1): 00513. Available at: http://medcraveonline.com/JPCPY/JPCPY-09-00513.pdf. Accessed March 28, 2021.

4. Cuncic A, Monahan M. How meditation can help generalized anxiety disorder. Available at: https://www.verywellmind.com/the-benefits-of-meditation-for-generalized-anxiety-disorder4143127\#citation-5. Accessed 29 March 2021.

5. TMBOS (World Traditional Medicine Web). Jin's Three Needles for obesity therapy (Chn). [世界传统医药网。靳三针治疗肥胖症]Available http://tmbos.com/index/article/view/id/10255.html. Accessed 31 March 2021.

6. Zhang H. Jin's Three Needles (J3N) Points Formulae. Available at: https://zhang.ac/index.php/2020/01/08/jins-three-needles-j3n-points-formulae/Accessed 29 March 2021.

7. Barber J. Traditional Chinese Medicine Appears Useful for Obesity-Medscape Apr 19, 2012. Available at: https://www.medscape.com/viewarticle/762306. Accessed 31 March 2021.

8. Ningtyas LAW, Widyastari S, Putri KE. Effectiveness of Thread Lift Use With Jin's 3 Needle Method On Overweight [Efektivitas Penggunaan Thread Lift dengan Metode Jin's 3 Needle Pada Overweight]. Jurnal Keterapian Fisik, 2018; 3(1), 1-8. Available at: https://doi.org/10.37341/jkf.v3i1.99. Accessed 30 March 2021.

9. Yao JP, He ZQ, Chen Y, Xu MM, Shi YZ, Zhang L, Li Y. Acupuncture and weight loss in Asians: a PRISMA-compliant systematic review and meta-analysis. Available at: https://journals.lww.com/md-

journal/fulltext/2019/08160/Acupuncture_and_weight_loss_in_Asians_A.51.aspx. Accessed 31 March 2021.

10. Luppino FS, de Wit LM, Bouvy PF, et al. Overweight, obesity, and depression: a systematic review and meta-analysis of longitudinal studies. Arch Gen Psychiatry. 2010 Mar;67(3):220-9. Available at: Overweight, obesity, and depression: a systematic review and meta-analysis of longitudinal studies - PubMed (nih.gov). Accessed: 23 Sept. 2021.

11. Chen AL. Jin's Three Needles combined with salt cushioned moxibustion in the therapy of central type phlegm dampness obesity: a clinical observation. (Chn) [陈爱玲。靳三针结合隔盐灭治疗痰湿型中心性肥胖的临床观察]. Available at: http://cdmd.cnki.com.cn/Article/CDMD-10572-1018274178.htm. Accessed 31 March 2021.

12. Xia Q. Section 3 Fourteen Meridians. In: Wang Xinhua's Textbook of traditional Chinese medicine. Science Publisher. Beijing. 2016:244-272.

13. Güçel F, Bahar B, Demirtas C, Mit S, Cevik C. Influence of acupuncture on leptin, ghrelin, insulin and cholecystokinin in obese women: a randomized sham-controlled preliminary trial. Acupunct Med. 2012 Sep; 30(3):203-7. Available at: https://pubmed.ncbi.nlm.nih.gov/22729015/. Accessed 01 April 2021.

14. Sui Y, Zhao HL, Wong VCW, Brown N, Li XL, Kwan AKL, Hui HLW, Ziea ETC, Chan JCN. A systematic review on use of chinese medicine and acupuncture for treatment of obesity. Available at: https://onlinelibrary.wiley.com/doi/abs/10.1111/j.1467-789X.2011.00979.x. Accessed 31 March 2021:

15. Amiri S, Behnezhad S. Obesity and anxiety symptoms: a systematic review and meta- 
analysis.

Neuropsychiatr. 2019

Jun;33(2):72-89.

Available

at:

https://pubmed.ncbi.nlm.nih.gov/30778841/. Accessed 29 March 2021.

16. Lykouras L, Michopoulos J. Anxiety disorders and obesity. Psychiatriki. Oct-Dec 2011;22(4):307-13. Available at: https://pubmed.ncbi.nlm.nih.gov/22271843/. Accessed 29 March 2021.

17. Goyal M, Singh S, Sibinga EMS, Neda F, Gould F, Rowland-Seymour A, et al. Meditation programs for psychological stress and well-being: a systematic review and meta-analysis. JAMA Intern Med. 2014;174(3):357-368.

Available

at: https://jamanetwork.com/journals/jamainternalmedicine/fullarticle/1809754. Accessed 1 April 2021. 